\title{
Reflexões sobre o uso do livro didático nas aulas de História (ensino fundamental e ensino médio)
}

\author{
Reflections on the use of textbooks in History classes (elementary and high \\ school)
}

Reflexiones sobre o uso del libro didáctico en las clases de Historia (enseñanza primaria y secundaria)

\author{
Jônatas Marques Caratti ${ }^{1}$ \\ Yasmim Fagundes Centeno ${ }^{2}$
}

\begin{abstract}
Resumo
Este presente artigo tem por objetivo analisar o livro didático em sala de aula, tanto do Ensino Fundamental como do Ensino Médio, buscando compreender seus diferentes usos e concepções. O livro didático é o principal suporte para o professor lecionar, porém, normalmente seu uso é limitado e pouco explorado. O objetivo é relatar algumas histórias do uso do livro didático em seu contexto escolar e refletir a partir de diversos autores sua utilidade e como o mesmo é visto numa visão mercadológica.
\end{abstract}

Palavra - Chave: Ensino de História; Livro Didático; Material didático; Mercadoria; Sala de aula

\section{Resumen}

Este artículo tiene por objetivo analizar el libro didáctico en el aula, tanto de la Enseñanza Fundamental y de la Enseñanza Media, buscando comprender sus diferentes usos y concepciones. El libro didáctico es el principal soporte para el profesor enseñar, pero normalmente su uso es limitado y poco explorado. El objetivo es relatar algunas historias del uso del libro didáctico en su contexto escolar y reflejar a partir de diversos autores su utilidad y cómo lo mismo es visto en una visión mercadológica.

Palabra - Clave: Enseñanza de Historia; Libro Didáctico; Material didáctico; Mercancía; Aula

\begin{abstract}
This article aims to analyze the didactic book in the classroom, both in primary and secondary education, seeking to understand its different uses and conceptions. The textbook is the main support for the teacher to teach, however, normally its use is limited and little explored. The objective is to report some stories about the use of the textbook in its school context and to reflect from several authors its usefulness and how it is seen in a marketing vision.
\end{abstract}

Keywords: History Teaching; Didactic Book; Educational material; Merchandise; Classroom

\footnotetext{
${ }^{1}$ Doutor em História pela UFRGS; Universidade Federal do Pampa; Jaguarão/RS - Brasil; jonatascaratti@gmail.com.

2 Graduanda do Curso de Licenciatura em História da Universidade Federal do Pampa - Campus Jaguarão. Rio Grande do Sul, Brasil. E-mail:minyebanho11@gmail.com
} 


\section{Introdução}

Como futura professora, da rede pública e/ou privada, dos anos finais do Ensino Fundamental e Ensino Médio, passei a refletir sobre o que poderia ser feito para sanar a falta de didática que os cursos de Licenciatura em História (são poucas disciplinas de formação pedagógica) não nos oferecem. Minha questão para complementar a carência foi de imediato trabalhar na pesquisa do meu TCC (Trabalho de Conclusão de Curso) sobre o Ensino de História. Tive em algumas de minhas leituras, como por exemplo, no texto de Marisa Lajolo “LIVRO DIDÁTICO: um (quase) manual de usuário”, o interesse pelo livro didático.

Neste artigo, quero trazer a questão de meu interesse, nas suas formas de usos em sala de aula por meio de autores que retratam o tema, ainda pouco discutido no âmbito nacional. Segundo Freitas \& Rodrigues(2007), o livro didático começou a ser inserido nas escolas na década de 1920, a partir do Instituto Nacional do Livro (INL). Esse órgão era responsável por legislar a política do livro didático. Depois disso, em 1938, durante o primeiro período do governo Getúlio Vargas, o livro didático recebe a primeira legislação para tratar de sua produção, controle e distribuição do material didático.

Segundo Gatti Júnior (2004), a partir da década de 1960, houve uma “massificação do ensino brasileiro" e os manuais escolares da década anterior foram substituídos pelos livros didáticos mais modernos. Sua história se inicia no século XV, antes da invenção da imprensa, onde os manuais escolares eram escritos pelos próprios alunos. O livro era uma peça rara e só quem tinha contato eram os nobres, pessoas de classe mais alta da sociedade. Com a imprensa os livros demoravam menos tempo a ficarem prontos, o que anteriormente era feito por copistas.

Não me atentarei, por enquanto, na história de criação e legislação do livro didático, pois neste texto meu foco fica restrito somente na utilização deste como manual do professor, sua utilização no contexto escolar como material didático e sua função mercadológica.

\section{Livro Didático como manual do professor/professora}

Antes de adotar um livro didático,

pergunte criticamente

se não vais ser um professor apático!

Ezequiel T. da Silva 
A palavra "didático" no dicionário significa "instruir". Segundo conceitos pedagógicos, "didática" tem por objetivo ensinar métodos e técnicas de aprendizagem aos alunos através dos professores.

Segundo Lajolo (1996), didático é o livro que é utilizado nas salas de aulas e que foi elaborado seguindo essa utilização escolar e sistemática. No Brasil, onde a educação é precária, o livro didático acaba determinando os conteúdos e estratégias de ensino. De acordo com a autora, "Como sugere o adjetivo didático, que qualifica e define um certo tipo de obra, o livro didático é instrumento específico e importantíssimo de ensino e de aprendizagem formal". (LAJOLO, 1996, p. 4); ou seja, voltando a metodologia utilizada, os exemplares pedagógicos utilizados em sala pelo docente acaba sendo único no sentido educacional, de maneira que o professor esgota seu conhecimento passado de ano a ano, perdendo o interesse de criação de materiais didáticos quando seu uso fica restrito a utilização do mesmo.

Conforme afirma José Carlos Libâneo, "uma boa didática, na perspectiva da mediação, é aquela que promove e amplia o desenvolvimento das capacidades intelectuais dos alunos por meio dos conteúdos" (LIBÂNEO, 2011, p. 3)

Embora o livro didático não seja o único material didático que docentes e principalmente, discentes utilizam nesse processo de ensino e aprendizagem, este é "decisivo" para a qualidade da aprendizagem. De acordo com Ezequiel T. da Silva (1996), o livro serve como uma "muleta" para a grande maioria dos formadores, assim a autoridade do mesmo fica quase que nulo na escolha de seu conteúdo. Nas palavras do autor "a intermediação desses livros, na forma de costume, dependência elou 'vício', caracteriza-se como um fator mais importante do que o próprio diálogo pedagógico" (Silva, 1996, p. 11), ou seja, em vez de haver uma interação com o preceptor a fim de sanar o ensino-aprendizagem do estudante, o livro didático assume esse papel de mediador se utilizando de conteúdos inscritos.

Não poderia deixar de salientar que, a maior parte dos educadores deseja o melhor para seu educando, por mais "limitações" que se tenha, como por exemplo: pouco tempo para a elaboração das aulas, falta, muitas vezes, de material complementar, como aparelho de som, data show, aparelho de vídeo e etc., e principalmente a desvalorização de seu trabalho.

Segundo Libâneo, há vários tipos de professorado; o "professor transmissor de conteúdo", que é aquele em que todos os seus métodos de aulas são iguais, independente da condição de cada aluno, passar conteúdos e aplicar questões de estudo para a prova; o “professor facilitador”, tipo de professor/professora que se julga atualizado, sua metodologia de ensino é variada; poderia citar aqui inúmeros tipos de professores que o autor comenta, mais já dito acima nosso foco é o livro didático. 
Assim como existe três tipos, segundo Fernando Becker, de modelos de relação entre ensino e aprendizagem. Segundo o autor os modelos pedagógicos dividem-se em: pedagogia diretiva - que vai de encontro com o "professor transmissor", aquele que fala a aula todo sem interação com os alunos; pedagogia não diretiva - o professor não diretivo é aquele que interfere o mínimo possível na aprendizagem do aluno, é aquele que acredita que o aluno aprende sozinho, por sí só; e pedagogia relacional - não fica restrito somente no "professor facilitador", é aquele professor que interage com os educandos de forma variada, ou seja, se utilizando de métodos pedagógicos diferentes e interagindo com o mesmo de forma abertamente.

O livro, neste caso, o didático, divide-se em: Livro do professor e livro do aluno; o livro do aluno é aquele destinado aos alunos de igual formato e conteúdo, o livro do professor, embora pareça o mesmo, internamente possuí questões e atividades diferenciadas para ser trabalhado com os alunos. De acordo com Lajolo (1996), o professor é um leitor privilegiado, já que a escolha do mesmo é feita por ele.(LAJOLO, 1996,p. 5)

Tanto o livro didático como a forma/maneira que o educador trabalha, tem que ser levada de forma com que os dois interajam simultaneamente, para que o receptor final, no caso o aluno, que é o maior beneficiário, possa aprender. O livro muitas vezes é o principal suporte de conhecimento e leitura dos estudantes. Para assim Lajolo: "Se através do livro didático o aluno vai aprender, é preciso que os significados com que o livro lida sejam adequados ao tipo de aprendizagem com que a escola se compromete”. (Marisa Lajolo 1996, p. 6)

Segundo Silva(1996), o livro didático não pode ser trabalhado por seu mestre de forma unitária, ou seja, utilizado de forma exclusiva e que "adota" o livro didático como principal forma de educação. Segundo o autor, "Didáticos são livros destinados a informar, orientar e instruir o processo de aprendizagem. Livros didáticos não educam!”. (Silva, p. 13). Da Silva ainda nos convida a pensar que sua utilização escolar está ou está tentando ser, ultrapassada, no sentido de que, com a introdução de salas de informática nas escolas e com o avanço da tecnologia, em algumas edições de livro didáticos, as mídias digitais já estão sendo inseridos como material didático a fim de extinguir com os livros didáticos, "Dá para coçar a cabeça e hesitar em uma resposta, quando a tecnologia vem conseguindo prensar um único CD-ROM cerca de 200.000 páginas de texto impresso". (Silva, p. 13). Não posso deixar de fazer um questionamento na questão da tecnologia, mas, será que os professores estão aptos a educação tecnológica?. Sabemos que o texto de Silva é um texto datado, que se refere a tecnologia de fins da década de 1990. Contudo, sua reflexão ainda é importante porque, de fato, a 
tecnologia coloca o livro didático como antiquado. E essa questão ainda se coloca em nosso cotidiano escolar, principalmente por colocar em xeque a função e os usos do livro didático atualmente.

Em contrapartida, Lajolo(1996) complementa a carência do livro didático com a experiência do professorado, é preciso planejamento na utilização do mesmo e estabelecendo um diálogo entre educador e educando, afirma Lajolo, “é só a partir disso que se pode descobrir a melhor forma de estabelecer o necessário diálogo entre o que diz o livro e o que pensam os alunos" (Marisa Lajolo (1996), p. 6)

Segundo Carmem Teresa Gabriel, uma forma de deixar o livro didático de lado, é trabalhando com fontes primárias em sala de aula, por dois motivos: motivar os alunos e exercer a autonomia do professor. Primeiramente. Motivar os alunos oferecendo um material mais concreto e que os estudantes muitas vezes não tem acesso(em muitos casos, as fontes primárias são guardadas em arquivos, museus e bibliotecas). Assim, as fontes têm o poder de despertar o interesse a curiosidade do aluno, pois são a própria fonte do historiador, permitindo que os mesmos entendam a construção do fato histórico. E em segundo lugar, exercer a autonomia, concordando com Silva e Gabriel, dos educadores na elaboração de suas aulas interagindo mais diretamente com seus discípulos, que como já dito o beneficiário mais importante. Seguindo a afirmação de Montelato, Cabrini e Catelli(2000):

\footnotetext{
"Peça fundamental na estrutura da obra, esta seção valoriza um dos instrumentos básicos do exercício do historiador: a análise dos documentos. A atividade nos permite o acesso a mais de uma interpretação da história e/ou o conhecimento dos diferentes sujeitos e projetos em conflitos num determinado contexto histórico".(Carmem T. Gabriel, p, 257)
}

Ao terminar este ponto, encerro concordando com Silva(1996), de que não é minha intenção pôr a culpa no professor, o que estou tentando "corrigir" é que o professor precisa ter mais autonomia em sala de aula e que o erro está na desvalorização do magistério. No Brasil, desde a década de 1980, mais especificamente em 1985,com a criação do PNLD, o país tem investido enormemente em livros didáticos, sempre atualizados, mas não valoriza a formação continuada.

"O mal necessário resulta de um conjunto de determinantes negativos na esfera do trabalho docente, dentre os quais a mania do livro didático. É hora de jogar a muleta fora! É hora de caminhar sobre as próprias pernas, com autonomia e decisão!’(Ezequiel T. da Silva, p. 14)

Ao terminar este ponto, encerro com a citação acima de Ezequiel T. da Silva que resume um pouco o que tentei explicar. O livro precisa ser deixado de lado para que a 
oportunidade do novo, no sentido disciplinar escolar, possa ser inserido sem medo de criar perspectivas, como a expansão do conhecimento acadêmico, para os alunos e assim e não mais, a instituição.

\section{O que é material escolar?}

Neste subtítulo, dedico-me exclusivamente a explicar o que é material escolar através do texto de Marisa Lajolo. Segundo a autora, "a escola é um lugar especial”, tão pouco especial também é o material escolar.

Porque material escolar, todo o material que está a disposição na escola é um material escolar, posso selecionar aqui vários tipos de materiais escolares, como: livros, cadernos, computadores, lápis, giz, aparelho de vídeo e etc. Segundo Lajolo, é tudo aquilo que faz parte da aprendizagem dos alunos; alguns desses materiais como o computador é mais raro em algumas escolas brasileiras, até o mais comum como o giz. De todos esses citados acima o mais comum e que tem um contato maior com os educandos, é o livro, e nesse caso o livro didático. Mas por que será que o livro didático é tão presente nas escolas? É o que veremos a seguir.

\section{O Livro Didático como mercadoria}

Em 1985, foi criado o Plano Nacional do Livro Didático(PNLD), seu objetivo é adquirir e distribuir livros didáticos para toda a rede pública, sua distribuição é feita gratuitamente para todos os alunos da rede pública. Sua política de planejamento, compra, avaliação e distribuição é feita pelo Fundo Nacional de Desenvolvimento da Educação(FNDE), programa este vinculado ao Ministério da Educação(MEC).

Segundo Célia C. Figueiredo Cassiano(2004), a circulação dos livros didáticos no Brasil é gigantesca, isso acontece por que o livro didático fica restrito no ensino aprendizagem dos aprendizes. Ainda, de acordo com a autora, antes do livro chegar ao beneficiário final, o aluno, precisa passar por no mínimo um estágio principal: escolha da obra.

A escolha da obra, é feita pelo professor através dos Guias de Livros Didáticos, esse guia tem função de orientar o docente na escolha do mesmo. A criação do Guia de Livros Didáticos, proposta pelo fato de que os livros didáticos estavam sendo enviados para as escolas com erros, segundo Cassiano(2004), erros conceituais, preconceituosos e 
desatualizados; por esse motivo o MEC realizou algumas pesquisas com os livros mais solicitados pelos mestres e escolas, divulgando os resultados no Guia de Livros Didáticos para orientá-los.

Segundo Circe Bittencourt(2009), o professor decide sua forma de compra e utilização, o aluno "público-alvo" é denominado pela autora de "comsumidor compulsório". "Sua confecção segue os princípios do sistema de avaliação", ou seja, sua escolha é feita através do Guia que é selecionado pelo Estado, "e é o principal comprador desse material", nesse casso o aluno, já que o mesmo é destinado a ele.

No campo industrial, Kazumi Munakata(2012) sintetiza em seu artigo que o autor não tem autonomia relativa, devido as obras escolares serem feitas em conjunto, ou seja, são vários autores trabalhando em uma obra somente.

Há toda uma estrutura industrial por trás do livro didático, começando pela escrita dos autores, revisão e preparação do texto, assim afirma Munakata(2012):

\footnotetext{
"Do ponto de vista editorial, um bom livro não é apenas aquele que contenha um bom conteúdo, 'sério', mas o que seja bem-feito - bem-feito não apenas em relação à exatidão das informações ou da ortografia, mas também no que respeita à coerência do estilo e da normalização".(Munakata, 2012 p.56)
}

A escolarização tornou-se direito de todos e obrigação do Estado, que segundo o autor o ensino é publico, gratuito, laico e obrigatório. A Constituição de 1988 garante a educação como direito de todos e dever do Estado, conforme o artigo 206:

Art. 206. O ensino será ministrado com base nos seguintes princípios:

I - igualdade de condições para o acesso e permanência na escola;

II - liberdade de aprender, ensinar, pesquisar e divulgar o pensamento, a arte e o saber;

III - pluralismo de idéias e de concepções pedagógicas, e coexistência de instituições públicas e privadas de ensino;

IV - gratuidade do ensino público em estabelecimentos oficiais;

V - valorização dos profissionais da educação escolar, garantidos, na forma da lei, planos de carreira, com ingresso exclusivamente por concurso público de provas e títulos, aos das redes públicas;

VI - gestão democrática do ensino público, na forma da lei;

VII - garantia de padrão de qualidade.

VIII - piso salarial profissional nacional para os profissionais da educação escolar pública, nos termos de lei federal. 
Garantido pela Constituição mas não praticado pela maioria dos governos, a educação continua sendo precária e os professores desvalorizados. O livro então passa a ser, com essa expansão do ensino, a principal mercadoria escolar. Portanto pergunto, senhor ou senhora leitor ou leitora, o livro didático é ou não uma mercadoria? E como seres humano que somos, consumidores ou não? De acordo com dados de 2009, da Câmara Brasileira do Livro, foram produzidos 386.367.136 exemplares de livros, vejamos na tabela abaixo:

\section{Tabela 1}

\begin{tabular}{|l|l|l|}
\hline & TOTAL DE LIVROS & VALORES EM VENDA \\
\hline $\begin{array}{l}\text { PRIMEIRA EDIÇÃO E } \\
\text { REEDIÇÃO }\end{array}$ & 202.643 .531 & 1.65 BILHÕES DE REAIS \\
\hline OBRAS DIDÁTICAS & 183.723 .605 & 1.73 BILHÕES DE REAIS \\
\hline TOTAL DE VENDAS & & 3.38 BILHÕES DE REAIS \\
\hline
\end{tabular}

Fonte: Dados coletados do artigo "O livro didático como mercadoria", de autoria de Kazumi Munakata da revista "ProPosições" V. 23, N. 3 de 2012.

\section{Considerações finais}

Neste artigo busquei trazer informações a respeito de como o livro didático é construído e elaborado, e mesmo com o avanço da tecnologia, ele se mantém como principal fonte e suporte de ensino dos professores. O foco da utilização do mesmo ficou restrito especificamente ao ensino público, que no Brasil, o ensino é precário e fica restrito ao mesmo, sem que docentes possam ter dignidade para desempenhar seu papel de forma segura do conteúdo que vai passar e ao mesmo tempo o discente, que fica restrito na aprendizagem tradicional de copiar o que já está exposto no livro, que de certa forma é seu, sem poder interagir com o professor de forma aberta e segura de suas dúvidas.

No entanto, quero salientar que o aumento da tecnologia fica na porta de fora de algumas escolas públicas do Brasil, num país em desenvolvimento onde a inserção dos computadores escolares é precário, no século XXI, a utilização do livro didático é cada vez mais abundante. $\mathrm{O}$ ensino fica restrito apenas na leitura do mesmo, que em muitos casos, constam informações erradas e que o mediador, no caso o professor, não interfere e reproduz o erro. Nesse sentido o professor, como já foi dito, é acima de tudo desvalorizado em sua profissão, chamando a atenção para a formação continuada do mesmo para que a educação, como consta na Constituição, possa ser laica, e de igual para todos. 


\section{Referências}

CASSIANO, Célia C. Figueiredo. Aspectos políticos e econômicos da circulação do livro didático de história e suas implicações curriculares. História. São Paulo, 2004

BITTECOURT, Circe. Livro didático. In: BITTENCOURT, Circe. Ensino de História fundamentos e métodos. São Paulo: Cortez, 2009.

DA SILVA, Ezequiel Theodoro. LIVRO DIDÁTICO: do ritual de passagem à ultrapassagem. Em Aberto, Brasília. Ano 16, n. 69, 1996.

BECKER, Fernando. Modelos pedagógicos e modelos epistemológicos. BECKER, Fernando. Educação e Construção do conhecimento. Porto Alegre: Penso Editora, 2012

FREITAS, Neli Klix; RODRIGUES, Melissa Haag. O livro didático ao longo do tempo: a forma do conteúdo. CEART-UDESC. Santa Catarina, 2007.

GABRIEL, Carmen Teresa. "Exercícios com documentos" nos livros didáticos de história: Negociando sentidos da história ensinada na educação básica. In.: ROCHA, Helenice A. Bastos; REZNIK, Luís; MAGALHÃES, Marcelo de S.(Orgs.). A história na escola: autores, livros e leituras. Rio de Janeiro: Editora FGV, 2009.

GATTI JUNIOR, Décio. A escrita da história: livro didático e ensino no Brasil (1970-1991). Bauru-SP, 2004.

LIBÂNEO, José Carlos. Didática e Trabalho Docente: a mediação didática do professor nas aulas. 2011.

LAJOLO, Marisa. LIVRO DIDÁTICO: um (quase) manual de usuário. Em Aberto, Brasília. Ano 16, n. 69, 1996.

MUNAKATA, Kazumi. O livro didático como mercadoria. Pro-Posições, V. 23, n. 3. 2012 